\title{
IPS E.Max-CAD Endocrown: Bonding steps
}

\author{
Debbabi Imen $^{1 *}$, Nouira Zohra², Ben Moussa Anissa ${ }^{2}$, Harzallah Belhassen ${ }^{2}$ and Cherif Mounir ${ }^{3}$ \\ ${ }^{1}$ DDM, Department of Fixed Prosthodontics, Faculty of Dental Medicine, Tunisia \\ ${ }^{2}$ Professor, Department of Fixed Prosthodontics, Faculty of Dental Medicine, Tunisia \\ ${ }^{3}$ Professor And Head of Department, Department of Fixed Prosthodontics, Faculty of Dental Medicine, Tunisia
}

*Corresponding Author: Debbabi Imen, DDM, Department of Fixed Prosthodontics, Faculty of Dental Medicine, Tunisia.

Received: August 30, 2019; Published: September 27, 2019

DOI: $10.31080 /$ ASDS.2019.03.0657

\section{Abstract}

Current ceramic materials offer preferred optical properties for highly aesthetic restorations. The inherent brittleness of some ceramic materials, specific treatment modalities, and certain clinical situations require resin bonding of the completed ceramic restoration to the supporting tooth structures for long-term clinical success.

The purpose of the present paper is to present the clinical bonding steps of an IPS e max cad endocrown fabricated by CAD/CAM system to restore a damaged first mandibular molar endodontically treated.

Keywords: Endocrown; CAD/CAM Restorations; Endodontic Treated Tooth; Ceramics; Composite Resins

\section{Introduction}

Endocrowns were first developed by Pississ in 1995 [1]. It is described as a monolithic full-composite or full ceramic overlays which restore partially or totally the coronal part of a devitalized tooth characterized by a supracervical butt joint, retaining maximum enamel to improve adhesion and extended inside the pulp chamber and partially inside the root canal with a short -endocore $[2,3]$. These restorations have micromechanical retention by being anchored to the internal portion of the pulp chamber and to the cavity margins and micro retention by adhesive cementation. It is an adhesive restoration with minimally invasive preparation [4].

This article describes the bonding steps of an endocrown destined to restore a dilapidated first mandibular molar endodontically treated.

\section{Presentation of clinical case}

A 20-year-old healthy female consulted the department of fixed prosthodontics at the dental clinic of Monastir to restore her damaged mandibular first right molar. The radiological exam showed that the tooth was endodontically treated (Figure 1).

We opted to an adhesive restoration with minimally invasive preparation. So we decided to perform lithium disilicate endocrown by CAD/ CAD system to restorate her dilapidated molar. The decision was taken with the patient's consent. The selection of shade before any intervention led to an A2 shade restoration (Figure2).

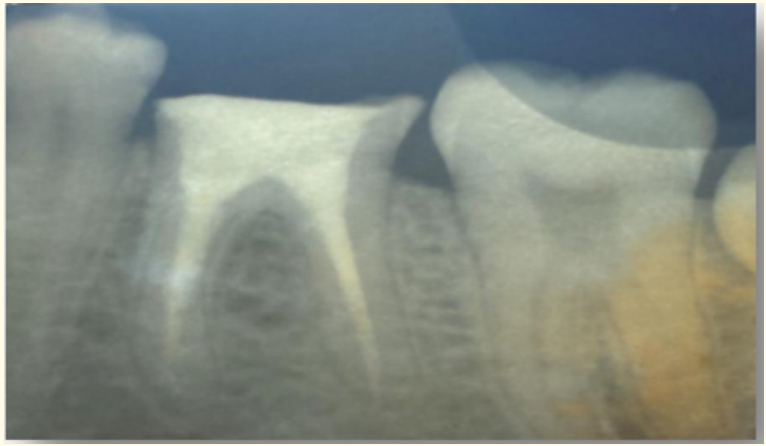

Figure 1: Radiological examination.

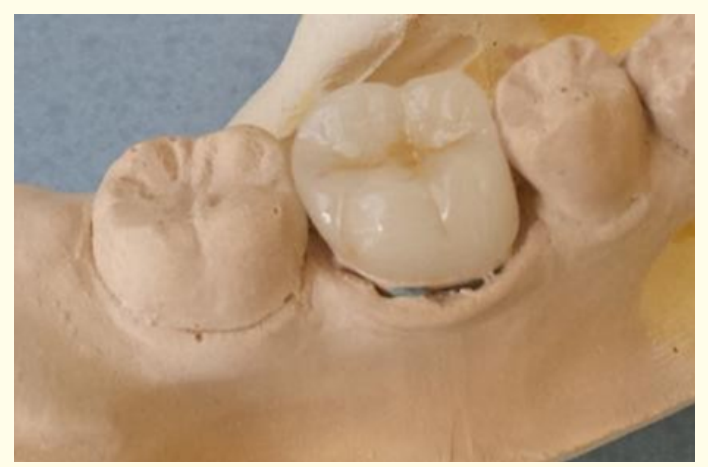

Figure 2: Endocrown (IPS e.max CAD) seated on working cast. 


\section{A step by step bonding procedure}

The marginal integrity and shade of the restoration were tested before cementation. A total etch dual cure resin luting cement (Multilink $^{\circledR}$ Automix) was used due to the presence of adequate enamel on the supragingival margins of the preparation. The bonding steps have been well applied and respected (Figure 3-4).

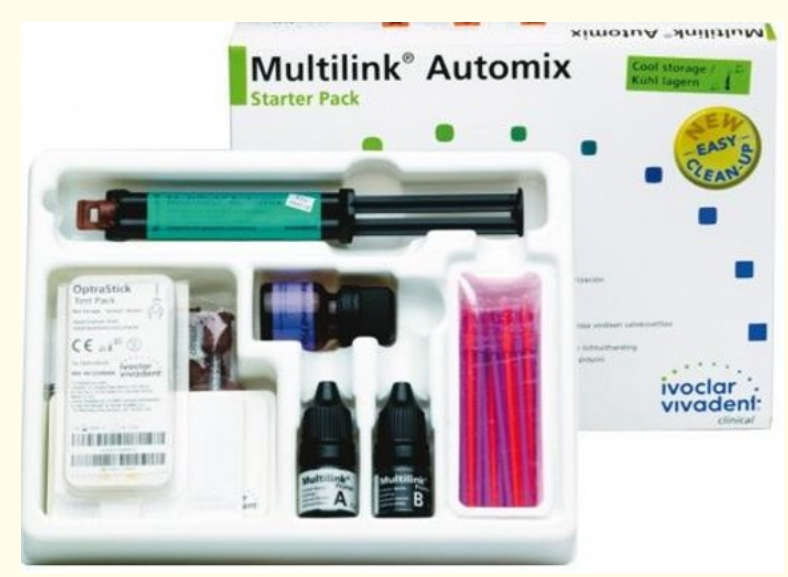

Figure 3: Bonding product (Multilink ${ }^{\circledR}$ Automix).
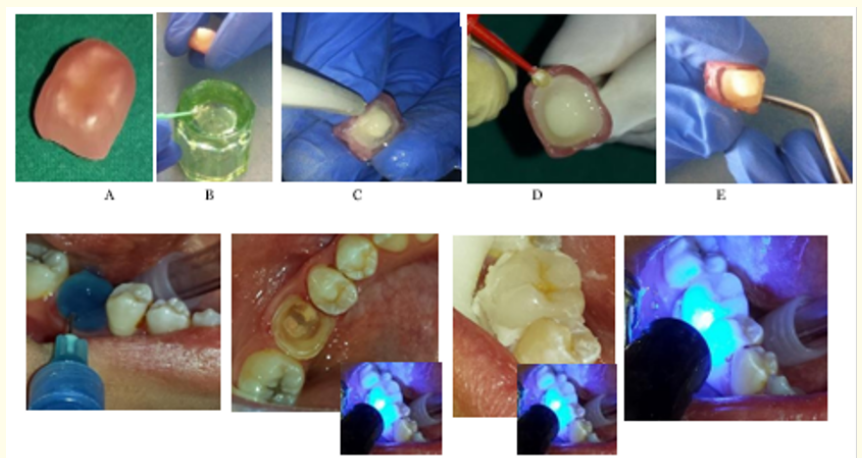

a
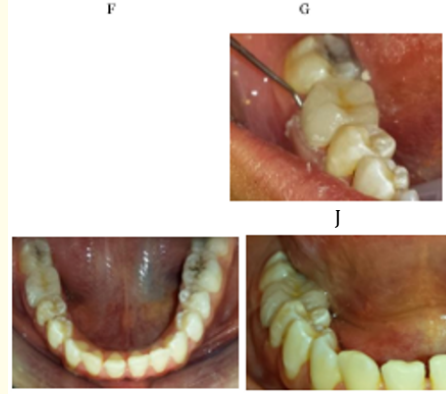

L

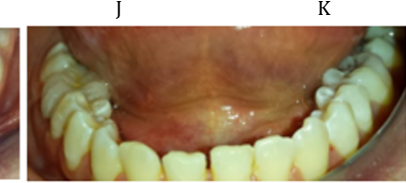

M
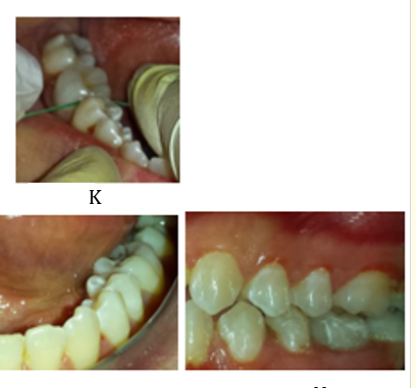

$\mathrm{N}$

Figure 4: A step by step bonding procedure.

(A) The external surface of the remaining preparation was Protected by using pink wax.

(B-C) Conditioning of the ceramic endocrown: The inner surfaces were etched using $9 \%$ hydro fluoride acid (HF) for $60 \mathrm{~s}$, then rinsed and thoroughly cleansed. The prothesis was Placed into a container of $95 \%$ alcohol and putted into an ultrasonic bath for four minutes to removany impurities that may interfere with the adhesion mechanism.

(D) The internal ceramic surface looked clear and had similar appearance of etched enamel,a bonding agent was applied without photopolymerization;

(E) The pink wax was removed

(F) The Conditioning of the prepared teeth was carried out by applying a $37 \%$ phosphoric acid etching gel for 30 seconds, as the preparation was within enamel, then rinsed off with water and dried until getting a frosty white appearance;

(G) the adhesive agent was applied and photopolymerized. A Light curing composite resin was used for cementation.

(H) The endocrown was gently positioned with finger pressure. The Correct seating was ascertained by checking the marginal fits. The Initial light cure lasted five seconds and then the excess of luting agent was removed.

(I) A final photopolymerization was performed for 60 seconds on the buccal and lingual surface of the restoration.

$(\mathrm{J}-\mathrm{K})$ The residual cement elimination was thoroughly assessed by probing the crevicular sulcus. Dental floss passes with light friction;

(L-M-N) Final result: Occlusal view - Front view and proximal view of the prosthesis in the mouth.

Static and dynamic occlusion were checked after Bonding the endocrown. Minor adjustments were realized using a fine diamond bur. In fine, the bonded endocrown was finished and polished. The patient was reviewed at 6,12 follow up periods. The restorations were characterized as acceptable, without any fractures . There was no clinical evidence that the existing crack expanded. The color match for the restoration was rated as Bravo.

\section{Discussion}

Over the years, the importance of tooth tissue preservation along with the evolution of dental materials has introduced new principles in the restoration of teeth leaving aggressive micromechanical approaches aside [5,6].

Initially, the materials for the fabrication of an endocrown were alumina or spinell reinforced non silica based ceramics and silica based feldspar ceramics [7] using either a heat-pressed technique or later CAD/CAM technology. Later, glass ceramics were the material of choice as they provide the advantage of surface modification, either with the use of hydrofluoric acid or air-abrasion, improving in that way their adhesion to the tooth tissues [8].

Vitroceramic has proven properties of biocompatibility with the gum; it is, moreover, mimetic [9]. The junction mode in this type of reconstruction must always have an adhesive component. It seems 
preferable to use materials containing the molecule MDP (10 -methacryloyloxy-decyl-dihydrogen phosphate) (ex: Panavia ${ }^{\circledR}, \mathrm{Ku}-$ raray Medical) or resins 4 META (4-methacryloxyethyl- trimellitatanhydrid) (ex : Super-Bond C and $\mathrm{B}^{\circledR}$, Sun Medical) or self-adhesive composite cements (eg RelyX ${ }^{\mathrm{TM}}$ Unicem, 3M ESPE) [10].

A total etch dual cure resin luting cement (Variolink II, Ivoclar Vivadent, Schaan, Liechtenstein) can be used if an adequate enamel on the supragingival margins of the preparation is present.

Since the margins were located at the gingival level, a less technique- sensitive resin luting cement must be applied (Rely-X Unicem, 3M ESPE, St. Paul, MN, USA) [8], a Self- adhesive resins which becomes more popular because of the fewer steps involved in bonding and ease of use [11].

The use of dual cement was justified by the fact that the lightcuring unit light needed to pass through the ceramic thickness [12].

The pulpal walls and micro retention provided micromechanical retention by the use of adhesive cementation. This added retention provided for the increased longevity and effectiveness of endocrowns [13].

It has been shown that endocrowns made of lithium disilicatebased ceramics are considered among the best restorative materials because of their adhesive properties; also, they promoted micromechanical interlocking with resin cement $[14,15]$.

The success and longevity of endocrowns also depend upon various other factors, such as operator skill, appropriate preparation techniques, adequate selection of most suitable ceramic options, and the choice of bonding material. In certain situations, endocrown has been rejected as a treatment option because of the lack of adhesive bonding and patients' economical constraint, as the main criteria [16].

Endocrowns can't be used in the following scenarios: [14] less than $3 \mathrm{~mm}$ pulp chamber depth [17], when adhesion cannot be assured [16]. If only negligible remaining tooth structure is present [18].

\section{Conclusions}

The development of adhesives cementation systems was a changing point in the restoration of Endodontically treated teeth and the need for macroretentive preparation for crowns has decreased [19].

The insertion of a radicular post is a less favored option as long as there is sufficient surface area for adhesion. Among the main factors related to the success and longevity of endocrowns is not only the selection of the adhesive system but also the respect of the protocol of cementation.

\section{Bibliography}

1. Pissis P. "Fabrication of a metal-free ceramic restoration utilizing the monobloc technique". Practical Periodontics and Aesthetic Dentistry 7.5 (1995): 83-94.

2. Rocca GT., et al. "Restoration of severely damaged endodontically treated premolars: The influence of the endo-core length on marginal integrity and fatigue resistance of lithium disilicate CAD-CAM ceramic endocrowns". Journal of Dentistry 68 (2018): 41-50.

3. Waad Alomran. "Endocrowns: A Review Article". Scholars Journal of Dental Sciences (SJDS)

4. Marwa EI Elagra. "Endocrown preparation: Review". International Journal of Applied Dental Sciences 5.1 (2019): 253-256.

5. Rocca GT and Krejci I. "Crown and post-free adhesive restorations for endodontically treated posterior teeth: from direct composite to endocrowns". The International Journal of Esthetic Dentistry 8 (2013): 156-179.

6. Konstantinos Tzimas., et al. "Endocrown restorations for extensively damaged posterior teeth: clinical performance of three cases". Restorative Dentistry and Endodontics 43.4 (2018): e38.

7. Bindl A and Mörmann WH. "Clinical evaluation of adhesively placed Cerec endo-crowns after 2 years-- preliminary results". The Journal of Adhesive Dentistry 1 (1999): 255-265.

8. Konstantinos Tzimas., et al. "Endocrown restorations for extensively damaged posterior teeth: clinical performance of three cases". Restorative Dentistry and Endodontics 43.4 (2018): e38.

9. M Fages., et al. "Endocouronne: les critères de réussite". les cahiers de prothèse 155 (2011).

10. E. D'incau., et al. "Traitement de la dent dépulpée postérieure. La stratégie de la preservation”. Réalités Cliniques 2.

11. Amal S., et al. "A Endocrown - An Overlooked Alternative Archives of Dental and Medical Research". 22.1 (): 273-280.

12. R Menezes-Silva., et al. "Endocrown: a conservative approach". Brazilian Dental Science 19.2 (2016).

13. Hew YS., et al. "Evaluation of pre-fabricated root canal posts". Journal of Oral Rehabilitation 28 (2001): 207-211.

14. GR Biacchi and RT Basting. "Comparison of fracture strength of endocrowns and glass fiber post-retained conven-tional crowns". Operative Dentistry 37.2 (2012): 130-136. 
15. MM Gresnigt M., et al. "Fracture strength, failure type and Weibull characteristics of lithium disilicate and multi-phase resin composite endocrowns under axial and lateral forces". Dental Materials 32.5 (2016): 607-614.

16. Selvanathan MJ Vinola., et al. "ENDOCROWN"_An Effective viabe Esthetic Option for Expurgated Endodontically treated Teeth:Two Case Reports". Journal of Operative Dentistry and Endodontics 2.2 (2017):97-102.

17. Hargreaves KM. “Cohen's pathways of the pulp”. St. Louis: Mosby. (2011).

18. Reeh ES., et al. "Reduction in tooth stiffness as a result of endodontic and restorative procedures". Journal of Endodontics 15.11 (1989): 512-516.

19. E Lander and D Dietschi. "Endocrowns: a clinical report". Quintessence International 39.2 (2008): 99-106.

Volume 3 Issue 10 October 2019

(C) All rights are reserved by Debbabi Imen., et al. 